\title{
Atlantis
}

Critical Studies in Gender, Culture \& Social Justice

Études critiques sur le genre, la culture, et la justice

\section{Affective Engagements in the Classroom: An Autoethnography of Exits and Openings}

\section{Maggie FitzGerald et Lauren Montgomery}

Volume 39, numéro 2, 2018

URI : https://id.erudit.org/iderudit/1064070ar

DOI : https://doi.org/10.7202/1064070ar

Aller au sommaire du numéro

Éditeur(s)

Mount Saint Vincent University

ISSN

1715-0698 (numérique)

Découvrir la revue

Citer cet article

FitzGerald, M. \& Montgomery, L. (2018). Affective Engagements in the Classroom: An Autoethnography of Exits and Openings. Atlantis, 39(2), 23-39. https://doi.org/10.7202/1064070ar
Résumé de l'article

We provide an autoethnography of gendered encounters in a graduate seminar. We use an affective lens to argue that these encounters stem from "more than" just individual sexism. We also use affect to identify how these encounters related to both exits from and openings for knowledge production in the classroom. 


\section{Affective Engagements in the Classroom: An Autoethnography of Exits and Openings}

Maggie FitzGerald is a doctoral student in the Department of Political Science at Carleton University.

Lauren Montgomery is a doctoral candidate in the Department of Sociology and Anthropology at Carleton University.

Abstract: We provide an autoethnography of gendered encounters in a graduate seminar. We use an affective lens to argue that these encounters stem from "more than" just individual sexism. We also use affect to identify how these encounters related to both exits from and openings for knowledge production in the classroom.

Keywords: affect; autoethnography; post-secondary education; knowledge production; graduate school

\section{Autoethnographic Prelude}

Maggie and Lauren: As two woman-identified graduate students running in similar critical political circles at our university, we had known each other for a few years, and were delighted to find ourselves in the same graduate seminar (especially as we are pursuing our doctoral degrees in different departments). Previously, in both classroom and social settings, we had shared a bond over feminist theory, and specifically theory related to care giving and emotional labour. We were both looking forward to extending previous conversations on these issues in this graduate seminar.

Unfortunately, the seminar did not unfold in a way that allowed for an extension of our prior conversations. Within the first few weeks, it became clear that other students did not welcome feminist issues or feminist interventions as avenues for discussion; insights from those students who identified as feminist were also not welcome. This was both shocking and dismaying to us - the course was a critical theory course, with entire weeks dedicated to issues such as social reproduction and colonialism (as well as a healthy dose of feminist theory scattered throughout segments on production, citizenship, and other topics). The professor, with whom we had both studied in the past, was a dedicated feminist, and we had witnessed his commitment to feminist theory in his pedagogy. In other words, all signs pointed to this seminar as a place for critical feminist engagement. This made it all the more troubling and confusing when we found that this space was anything but open to the types of critical feminist interventions we were hoping to explore.

At the end of one particularly frustrating class, we sought each other out, and hesitantly expressed our 
concerns about the seminar. We were both relieved and saddened to hear one another recount the same feelings of dismissal and disrespect from our (generally male) colleagues, and we shared a sense of disbelief regarding the unwillingness of the class to discuss feminist issues, even when they were a part of the assigned reading materials. Subsequently, we also realized that neither of us felt that we had the space in this class to engage with our own experiences with the texts; this, we felt, was unfortunate, as we both dedicated numerous hours each week to completing the required course readings (as well as some of the suggested readings).

As a result - and with a renewed energy having had our experiences in the class mutually validated-we decided to meet outside of class once a week to discuss the course texts, papers, and presentations. In that moment, we found ourselves, two critical feminist graduate students, exiting the classroom, and opening a new epistemic space.

\section{Introduction}

Post-secondary education is fraught with sexism and hegemonic masculinities, which often render spaces, including the classroom, hostile to those who do not carry the privilege of maleness, whiteness, ability, and so on (e.g. Baker 2012; Caplan 1993; Coleman 2005; hooks 1994; Kelly and Slaughter 1991; Kobayashi 1994; Kyvik and Teigen 1996; Mintz and Rothblum 1997; Uhly, Visser, and Zippel 2017). Although the neoliberalization of the university has (re)shaped these dynamics (Gannon et al. 2015), this phenomenon is not new; women, people of colour, queer people, people with disabilities, trans* and two spirit individuals, the poor, and marginalized people in general, have struggled since the establishment of post-secondary institutions to carve out space in the academy. This paper arises from our experiences as women graduate students at a Canadian university, and our encounters with the oppressive gendering of academic spaces. In particular, this exploration centres on our experience in a graduate level seminar class, which was dedicated entirely to critical theories of political economy. We argue that in this space, an affective plane emerged which shaped our interactions with our peers, and our production of knowledge as a class, in gendered ways that resulted in both exits (from the discussion, from the literal classroom space) and openings (to create new knowledge, to reflect on the university as a gendered space, to consider the role of affect), albeit in varied ways.

By employing an affective lens, we hope to foreground the interconnections between us as students (our experiences, our embodied being), our peers, the theory with which we engage, and the university space more generally. We do this by applying aspects of Dorothy Smith's $(1987 ; 2005)$ institutional ethnography in tandem with autoethnography to analyze two particular incidents that occurred during the class in question. These two incidents evolved around moments of disjuncture and tension between us and our academic peers. Our reflections on these incidents, of course, can in no way be thought of as summarizing the entirety of a semester's exchange among the students of this class. Rather, following the work of Kaela Jubas and Jackie Seidel (2016), we use these incidents to ground our analysis in our "everyday" encounters in the academic workplace, and to begin to answer the following questions: How do affective planes enable or constrain knowledge production inside and outside of the classroom? What are the productive (im)possibilities of affective exits and openings?

In exploring these questions, our analysis aims to use an affective lens to examine how knowledge production is shaped in the post-secondary education classroom. We suggest that by focusing on affective planes - the intangible connections between people, places, and things through which our ability to affect and be affected circulates - we can illuminate a key mechanism through which knowledge production is intimately linked to the ways in which spaces are gendered. This focus, we contend, moves us beyond an account of how individual sexist attitudes impact knowledge production in the graduate seminar by il- 
lustrating how the exchanges in a classroom are more than the sum of individual (gendered) interactions. An affective lens also helps us identify the productive potentialities of oppressive encounters. As we argue below, the affective plane which shaped our (negative) experience in the classroom also prompted us to find new (positive) space(s) from which to engage in knowledge production; as we exited one affective plane we were immediately immersed in another. In this way, we also see affect as that which might motivate us to move through tensions of exit and opening, of closure and beginning.

This paper is organized as follows. First, we present a note on our research method, drawing out how and why we combine the two approaches of autoethnography and institutional ethnography. Our intention in this section is to make explicit the methodological strengths and weaknesses of this work, while also situating our research in a tradition of inquiry which views research as fundamentally relational (Bondi 2003; Wilson 2008). Second, we explicate our understanding of affect and affective planes. This section is meant to provide the theoretical background from which our analysis and argument is constructed. We then provide two vignettes from the doctoral seminar (the seminar introduced in our autoethnographic prelude). Using these events as guides, we discuss the affective planes that emerged in the classroom at those two points in time-space. We explore how these affective planes provide an alternative lens from which to understand the ways in which the classroom space was gendered and, at times, even hostile. We discuss how, for us, this affective lens illuminates some of the ways in which gender-based oppression manifested in the classroom as more than personal attacks or individual sexist attitudes, and we explore how these affects constrained the mutual production of knowledge that we had hoped for-and indeed expect-in graduate seminars. Finally, we suggest that this affective plane thus corresponds to a variety of exits and openings: our peers "exiting" the conversation, us exiting the classroom, and perhaps most interestingly of all, us finding a new affective opening from which to (re)start knowledge production processes.

\section{A Brief Note on Methodology}

Carolyn Ellis, Tony Adams and Arthur Bochner (2011) explain that "autoethnography is an approach to research and writing that seeks to describe and systematically analyze (graphy) personal experience (auto) in order to understand cultural experience (ethno)" (n.p., italics in original). Similarly, Victor Jupp (2006) defines autoethnography as "a form of self-narrative that places the self within a social context" (15), while Heewon Chang (2008) describes autoethnography as a methodology that "combines cultural analysis and interpretation with narrative details" (46). This paper is built around such a method. We seek to employ an analysis and discussion of aspects of our shared personal experience in a graduate class so as to illustrate and better understand larger patterns of cultural experience and, specifically, patterns of academic cultural experience. We thus see autoethnography as "a radical form of making embodied knowledge claims" (Dutta 2018, 94); it is through a reflexive and critical engagement with our bodily inscribed experiences that we come to know. "Theory can do more the closer it gets to the skin" (Ahmed 2017, 10).

Given our use of autoethnography, concerns of reliability, generalizability, and validity (Ellis, Adams, and Bochner 2011) are naturally present. Memory is imperfect, and our recollections are necessarily incomplete, somewhat inaccurate, and potentially biased. However, we reject the idea of "universal truths" as sought in positivistic research, and instead follow the tradition of inquiry that understands qualitative research in general as a relational process (Bondi 2003), in which researcher(s), participant(s), writer(s) and reader(s) are mutual "constructors of knowledge" (Holstein and Gubrium 1997, 114). From this vantage point, we locate the generalizability of this research in the (potential) relationship it forms with the reader (Ellis and Bochner 2000), who can then reflect on the experience and the cultural patterns suggested by said experience. Put differently, we believe that the narratives presented here are generalizable in that the reader "will filter the story being told through their own experience and thus adapt the information to 
make it relevant and specific to their life" (Wilson 2008, 32).

We also acknowledge that all people who witness or experience the same event often describe the event in different ways (Tullis Owen et al. 2009); our presentation of events likely differs from the recollections of others in the classroom. Nonetheless, we have attempted to produce a reliable recollection by drawing upon notes taken during the class, and by carefully reflecting on the events explored here, both individually and together. In many ways, this reflective process highlights the fact that academics are simultaneously participants and researchers, subjects and objects, and foregrounds the ways in which these multiple roles contribute to knowledge production.

Finally, we believe that the validity of this work also lies in the hands of the readers, who "provide validation by comparing their lives to ours, by thinking about how our lives are similar and different and the reasons why, and by feeling that the stories have informed them about unfamiliar people or lives" (Ellis, Adams, and Bochner 2011). As Tami Spry (2001) explains, a good autoethnography can be judged based on the quality of the writing, and its "ability to transform readers and transport them into a place where they are motivated to look back upon their own personally political identity construction" (713). In this way, good autoethnography is that which is emotionally engaging, "a provocative weave of story and theory" (Spry 2001, 713) through which a "purposeful dialogue between the reader and the author" (Spry 2001, 713, italics in original) is created. Following from these criteria, and in the fullest sense, this exploration is intended to be a relational exchange of ideas between the reader and the writers, facilitated by literary craft and rich description of personal stories.

In order to link our experiences to broader social structures, we have put autoethnography in conversation with institutional ethnography (Smith 1987; 2005). Institutional ethnography "is an analytic approach that begins where we as actual people with bodies are located in time and space. It offers a theoretical approach to reflecting critically on what one knows from that embodied place in the world" (Campbell and Gregor 2008, 9). In this paper, we are analyzing a particular time, space, and place within our academic careers, and we are analyzing it from our embodied experiences as women located inside and outside of the classroom. Institutional ethnographers focus on understanding how our "everyday" experiences — such as work-are organized, and how relations that extend beyond the individual shape these experiences (Smith 1987; 2005). This method emphasizes that the individual knows and participates in social relations differently and, as a result, everyone has their own standpoint (Campbell and Gregor 2008).

By combining autoethnography with institutional ethnography, we are able to make links between the micro or local conditions of the graduate seminar and extra-local conditions, such as broader patterns of gendered spaces in academia. This, in turn, allows us to explicate how and why we experience the world in the way that we do (Taber 2010). Institutional ethnography begins with our experiences as individuals, and understands experience as both theory and data (Kinsman and Gentile 2010; Smith 2005; Taber 2010); it allows for experiences to be theory, rather than for experiences to be only theorized (Gould 2009; Smith 1987; 2005). Using institutional ethnography with autoethnography allows us to bridge the divide between personal experiences and the social (Jubas and Seidel 2016), to take our theory/experiences and link them to other social relations. ${ }^{1}$

\section{A Theory of Affect}

Affect is used in the literature in a variety of ways. Some scholars use affect interchangeably with words like emotion and feeling (Gannon et al. 2015). Furthermore, a significant body of work conflates affective labour with emotional labour, socially reproductive labour, and/or care work. ${ }^{2}$ In the words 
of Ben Anderson, "the term 'affect' is now . . . a contested one that is used in divergent ways across different literatures" (2006, 734).

Our understanding of affect largely follows Anderson's theory of affect. According to Anderson, affect is, first and foremost, the "transpersonal capacity, which a body has to be affected (through an affection) and to affect (as the result of modifications)" (2006, 735, italics in original). Importantly, this capacity, though presented here as two parts, is actually a singular capacity in which being affected and affecting are two sides of the same process. That is, when one affects, one is opened up to being affected, and vice versa. It is the necessary corollary of this that affect does not reside in anyone or anything. Rather, affect occurs through transitional exchanges and processes as objects/subjects encounter each other directly and indirectly; it "is produced only as an effect of its circulation" (Ahmed 2004, 120). Affect moves between bodies (Gannon et al. 2015). It is not an isolated capacity, but rather a transpersonal capacity in which affecting/being affected could not occur without the full interconnectedness between the self and the cosmos.

This understanding of affect is akin to Sara Ahmed's (2014) discussion of Martin Heidegger's (1995) notion of "mood" or "attunement." As Ahmed (2014) explains, for Heidegger, "mood [or attunement] is being in relation to others" (15):

Attunements are not side-effects, but are something which in advance determine our being with one another. It seems as though attunement is in each case already there, so to speak, like an atmosphere in which we first immerse ourselves in each case and which then attunes us through and through. (Heidegger 1995, 67, quoted in Ahmed 2014, 15, italics in original)

Mood/attunement, like the conceptualization of affect described here, serves as the atmosphere through which our relations unfold. It is a transpersonal capacity, a "withness" (Ahmed 2014, 15) that alwaysalready forms the possibility of affecting and being affected, albeit in different and complex ways.

The transpersonal nature of affect also emphasizes the material aspects of affect. Affect is deeply embedded in material processes, and involves material encounters, which link the self to all other matter. Like physical encounters between person(s) and object(s), which can be unevenly distributed across time-space, affect also has a distribution across and through bodies, objects, and space. "Being affected-affecting' emerge[s] from a processual logic of transitions that take place during spatially and temporally distributed encounters" (Anderson 2006, 735, italics in original). Just as encounters are often unevenly distributed, so too are affects (Gannon et al. 2015).

These affective encounters contribute to the composition of relations amongst and between individuals, groups of people, and objects (Anderson 2006). In fact, as Anderson (2006) argues, "the emergence of affect from the relations between bodies, and from the encounters that those relations are entangled within, make the materialities of space-time always-already affective" (736). All of our encounters are steeped in affect and involve being affected-affecting. This is significant, in that it precludes the possibility of affect being a linear process:

There is not, first, an 'event' and then, second, an affective 'effect' of such an 'event.' Instead, affect takes place before and after the distinctions of subject-world or inside-outside as a "ceaselessly oscillating foreground/background or, better, an immanent 'plane." (Anderson 2006, 736, quoting Seigworth 2000, 232)

Therefore, "to think through affect we must untie it from a subject or object and instead attune to how affects inhabit the passage between contexts through various processes of translocal movement" (Anderson 2006, 736). To reiterate, affect is not something one can possess; it is "not contained within the contours of a subject" (Ahmed 2004, 121). Instead, affect can be thought of as the "between" contexts - a plane in and through which our interactions are shaped, affected, and affecting. Given the particular emphasis in 
this paper on connecting personal experiences to broader institutional patterns, attending to affect facilitates this bridging.

Affect is also distinct from emotions, as emotions are the registering of an (or multiple) affect(s). Anderson (2006) writes:

Feelings always imply the presence of an affecting body: an affection is therefore a literal impingement of the emergence and movement of affect on the body (when the body can be anything). But the movement of affect is not simply received by a blank body 'in' space or 'in' time. Feelings act as an instantaneous assessment of affect that are dependent upon the affected body's existing condition to be affected. (736)

In other words, while emotions are "instantaneous assessments of affects," they are also dependent upon and shaped by "the affected body's existing condition to be affected." As being affected always involves affecting, emotions themselves have the potential to (re)produce affects. While each feeling may be instantaneous, feelings can involve residual impacts which will often intermingle with other affections. Because of this, feelings are also potential mechanisms through which new affective planes may emerge. The work of affect scholars like Ahmed (2014) and Ann Cvetkovich (2012) emphasize this interplay between emotions-feelings-affect. This interplay also helps to illustrate how and why affects and affective ecologies can emerge in unlimited forms and ways. These multiple affects and affective planes are often co-existing and interacting with/shaping a singular relation at once.

Finally, it is important to note that "emotions and affects are best understood as only weakly cognitive phenomena that straddle the merely individual and the broadly social" (Anderson and Holden 2008, 145). This statement contains two crucial points. First, emotions and affects are "only weakly cognitive phenomena," and are therefore not purely or wholly conscious experiences. People may register affects through instantaneous feelings, but the affection itself works on the edges of consciousness. Second, the fact that affect "straddle[s] the merely individual and the broadly social" means that affect and emotions are components of what Anderson and Adam Holden call "assemblages" (2008, 146). The word assemblage "designates the priority of neither the state of affairs nor the statement but their connection, which implies the production of a sense that exceeds them and of which, transformed, they now form parts" (Philips 2006, 108; also quoted in Anderson and Holden 2008, 157). Put differently, "assemblage" emphasizes the connection between subject(s), object(s), and place(s), and suggests that these connections involve a transformation in which the subject(s), object(s), and place(s) come to produce a sensation or affect. Assemblages indicate "a process of arranging, organizing, and fitting together multiple, heterogeneous, elements. Assemblages, therefore, bring together elements from a milieu, context, or surrounding" (Anderson and Holden 2008, 146). The role of affect in these assemblages further demonstrates how affect is one of the powerful forces linking together individuals, collectivities, and the cosmos. As Ahmed (2004) explains, it is this linking together, and the failure of affect to be located in singular, "that allows it to generate the surfaces of collective bodies" (128).

\section{Exploring Affect in/through Classroom Ex- periences}

With this conceptualization of affect in mind, we present two recollections for consideration. Both of these incidents occurred in a doctoral seminar in a Canadian university that included five women, four men, and a male professor, all from different academic units and disciplines. Two of the students were non-white, and the ages of the students spanned from the mid-twenties to the fifties. ${ }^{3}$ The two authors, as previously mentioned, were in this class together. Both authors begin from the embodied standpoint of two woman-identified doctoral students. Although we share many similar characteristics in terms of our subjectivity as white cis-gendered women, we differ in our financial backgrounds, our embodied dis/ability, 
and our engagement with heteronormativity. These subtle similarities and differences impact the ways in which we each navigate academic spaces-and the ways in which we are affected/affecting in the classroom.

Maggie: I was the first student to give a presentation in the seminar, covering the second week of assigned readings. I was nervous-as I always am when presenting-but particularly so given that I was the first student to present for this class. It can be both a negative and a positive to "go first." On the one hand, you have no template to follow, no earlier examples to go by. This can be intimidating and imposter syndrome is always quick to reassure you that your thoughts are not good enough. On the other hand, you get to be the template and may perhaps set the tone for the class, and even subsequent classes to come. There is a creative potentiality to this, an opportunity to contribute to and shape the structure of the class.

After much deliberation, I decided that I wanted to achieve two aims in the presentation. First, I wanted to summarize and explore the themes in the assigned readings, which involved a broad overview of the theoretical tradition of political economy. Second, and more importantly, I wanted to focus on the challenges of doing critical theory, like political economy, at this point and time in academia. My goal was thus to place the researcher/theorist/student at the center of the class: we do not passively discuss texts in graduate seminars. Rather, as feminist scholars like Ahmed (2017) contend, we do theory. By focusing on the embodied "doing" of theory, and the constraints placed on this "doing" by the academic institution, I wanted to ground the discussion not only in the texts but also in the bodies (us) that (re)produce and disrupt theory.

At the end of my presentation, I posed three questions based on the readings (and specifically my reading of the readings) to prompt the class discussion. One of these questions involved a discussion of neoliberalism. In line with my theme of "doing" theory, I was interested in how my peers experienced the neoliberalization of the university, and whether or not they felt that neoliberal norms present challenges for doing critical theory. What practical challenges do critical scholars face when doing "critical" work in a neoliberal institution that is increasingly concerned with quantity over quality? How does the individualization of the academy-from a space where people come together to collaborate on knowledge production to a place which is primarily concerned with individual citation indices and publication counts - disrupt (or alternatively open up space for) critical scholarship?

Upon concluding my presentation, and posing my discussion questions, the professor asked my peers if they had any questions for me based on my talk. A male colleague raised his hand and (correctly) pointed out that I had neither defined the term "neoliberalism," nor specified exactly how this term applies to the university. He asked if I could elaborate on this before the discussion began. I agreed that this term is oftused and rarely defined and explicated my understanding of the term (a set of norms which prioritizes individualism, competition, and quantity over quality) so that discussion could at least begin from a mutual starting point. The conversation then continued fruitfully; indeed, many of the students in the class were currently grappling with these questions as they were beginning to construct their doctoral dissertation projects while also navigating the competitive publish-or-perish mentality that so pervades our institutions.

Several weeks later in the course, we were discussing relations of production. A male colleague was commenting on one of the assigned 
readings and began talking about class relations in what I thought to be a vague manner. As a response to his commentary, I explained my particular understanding of class and asked him to explain his, so that I could engage with his ideas as best as possible; the way he had been mobilizing the term seemed contradictory to my understanding of class and I was struggling to comprehend his broader point because of this definitional gap. My colleague was visibly irritated by this (me); he moved from addressing the class more generally to speaking directly to me, while also ignoring the question by continuing to make his broader point. I contemplated letting my question go-I felt that the conversation was shifting towards confrontation-but ultimately, and in true "feminist killjoy" fashion (Ahmed 2017), ${ }^{4}$ I continued to press him to be clear. I'm not sure how this exchange was read by others in the class; my question had shifted the discussion from the group to the two of us in a way that I perceived to be somewhat hostile, and in a way that focused my attention completely on this particular colleague.

Finally (I suppose when it became evident that I was not going to drop the question), my colleague responded and defined class based on income brackets. This clarified much of my earlier confusion, as I generally understand class as centering on the wage-labour relation, in a very traditional Marxist sense. I decided to thank my colleague for his clarification, partly because his response had resolved my confusion and, more honestly, because I felt that the exchange had been heated and I wanted to cut the tension that was flooding the space.

To my dismay, however, my attempt at deescalating the exchange was unsuccessful. Unlike the encounter above, in which definitional clarity of the term "neoliberalism" enriched the discussion, this time, the conversation was completely stunted. Other students had had hands raised, waiting for a turn to provide their comments on the topic; these hands were quickly lowered and silence overcame the room. The professor, who kept a speakers' list for the class to ensure that everyone was given space to speak, consulted the list. The students who had been waiting passed on the opportunity when called. This encounter seemed to have produced such discomfort that no one wished to engage further with the topic; what could have been a productive discussion of class turned into stifled silence. At this point, I turned my attention back to the rest of the class, many of whom seemed to register the tension and abrupt halt as well. After unsuccessfully attempting to continue the dialogue by calling on those who had previously indicated a desire to speak, the professor suggested that this may be a good time to take our usual fifteen-minute break. The class enthusiastically (too enthusiastically?) concurred, and we variously headed to the restroom, coffee shop, or our individual offices before reconvening for the second half of the seminar.

This first recollection involves two incidents and spans two classes and several weeks. Nonetheless, we argue that, fundamentally, the core of these two incidents are very similar; one student used a term without explicitly identifying their understanding of this term; another student pointed out this omission and challenged the first student to elaborate clearly their particular use of the term. Despite this similarity, the outcomes of these two incidents were rather different. In the first case, conversation was enriched by this challenge and our theoretical discussion continued unhindered (or perhaps even enhanced) in this classroom space. In the second incident, however, a similar challenge stifled knowledge production and discussion completely. Upon reflecting on these exchanges, we were left wondering: How can these two similar exchanges result in such different outcomes?

Similarly, consider this second recollection: 
Lauren: Right before one class, about midway through the semester, we were informed by our departmental administrator that our professor was unexpectedly unable to join us for the seminar. He left a note asking us to go ahead with the class in spite of his absence, indicating that all of the students could together lead and facilitate the discussion. This included designating one person to manage a "speakers' list" (particularly important as our grades were significantly impacted by the participation portion of the class) and one student to take notes for the instructor on the nature of the discussion. These notes and the speakers' list were to be provided to the professor after the class. All of these tasks, and the responsibilities for following up with the instructor, were taken on by woman-identified members of the course, including Maggie and myself.

At this point in the semester, the tension among students had become quite noticeable, and rather than feeling excited to attend class (as I had been at the beginning of the term), I felt anxious and uninterested, particularly when it came to participating in class discussions. This was unusual for me. I love learning and I love political economy theory. I was excited to take this course as an opportunity to expand my knowledge of political economy theory, and to gain a more in-depth understanding of the core theories that comprise this field. At this point in my degree, I had already completed my course requirements, but I had decided to take this extra class for credit in order to expand my knowledge, to work on my writing skills, and to be challenged by my professor and my colleagues to engage in theoretically rigorous thought exercises. In other words, I had chosen to take this course for personal intellectual gain and interest.

When we received the note stating that the professor would not be attending and that the class was to self-organize that day, my heart immediately sank. I had a very distinct feeling of anxiety that the class would be both chaotic and tense, requiring a lot of emotional labour with little intellectual benefit. Frankly, I was worried about losing three hours of my day, and not getting the positive learning experience that I so desired. Despite the feelings of anxiety, I was committed to attending the class and resigned myself to stay.

The class began quite smoothly. At about the half-way mark, however, Maggie interrupted a male colleague who was speaking. While she did interrupt our colleague (breaking classroom etiquette), her tone was not confrontational; rather she made an intervention in the discussion that had theoretical and practical implications for how the class understood and debated the assigned readings, which were focused on the relationship between morality and the economy. After the interruption, our male colleague finished his thought, and the discussion proceeded despite this interruption for some time. Several minutes later, however, our colleague raised his hand and said, "I don't want a response to this, but notice that I was the only one who was interrupted during this discussion?" Maggie then apologized, as it was clear that the comment referred to her interruption, and acknowledged the wrong in her earlier actions. Yet, despite this apology, the conversation was again, completely stunted. An awkward silence ensued for some time, and it was only after much effort by the student-facilitators that class discussion resumed.

As the dialogue was picking up again, I was in the process of commenting on one of the assigned readings for the week. The same student that Maggie had interrupted cut me off to give his thoughts. While I attempted to re-assert myself, and stated that I would like to finish my thought, the majority of the class acted as if this interruption had not happened, and discussion continued, with other students jump- 
ing in to pick up on the point made by the male student. Unlike when a male student had been interrupted-causing an effective end to the conversation - the erasure of my voice did not even register for most of my colleagues.

Throughout my academic career, I have often spent time thinking about how to best engage in course discussions and class activities so that I can contribute to the learning space and collective knowledge creation by "raising up" my colleagues and supporting them. Indeed, I consider this a key factor in bringing feminist values and social justice practices into my "everyday" work (Ahmed 2017; Smith 1987). As Ahmed (2017) asserts, these practices are integral to the feminist movement; we must strive to build feminist tendencies into our everyday lives, and we must attempt to practice feminism, as opposed to simply speaking of feminism.

Given my personal goals of practicing feminist values when I engage in a class (a practice which often requires substantial emotional labour and reflection), I was quite frustrated and disappointed that so many of my peers were willing to allow the erasure of my participation in the course in this way. I was hurt that my classmates neither respected my voice, nor the expression of my ideas in this space. Furthermore, I was extremely exasperated that I had spent so much time preparing for class by analyzing five publications (articles and books) of theoretically dense material and constructing questions for clarification and discussion. I felt as though my efforts to be both a respectful classmate, as well as my academic labour to prepare for the course, had not just been dismissed; it had been completely devalued.

At this uncomfortable moment, I could not stay in this space. Instead, I promptly got up and removed myself from the classroom-a physical manifestation of an affective exit. I could begin to feel my face becoming red. My anxiety increased and my feelings of frustration began to bubble towards the surface. I chose to take my own ten-minute break in order to gain some perspective and space from the class and the individuals that were fuelling my frustration. I was also tired; I chose not to challenge this students' behaviour more forcefully because of my desire to avoid provoking or eliciting a (more) confrontational reaction. I could not expend any more emotional labour in that space at that time.

Of course, this ten-minute reprieve was not the end of this incident. The affective residue of the experience followed me home at the end of the day. I spent a significant amount of time that evening criticizing myself for not being more assertive, and for not asserting that it was my right to participate, and to be respected, in the course. I spoke to friends and my partner about the experience. And while these discussions helped, it also bred greater frustration; now I was spending time and emotional energy outside of the classroom processing the ways I had been affected in the class.

This recollection likewise involves two incidents; however, these occurred within a three-hour period (the length of one class). Again, we suggest that the fundamental exchanges and interactions in these two incidents are very similar. In both the first and second case, a student interrupts another student, who addresses this interruption. However, the outcomes vary significantly. In the first case, the conversation is cut off entirely and the mutual construction of knowledge that is meant to occur in graduate seminar spaces is inhibited. In the second case, the interruption did not stop the production of knowledge; rather, it simply changed who was able to participate.

These two recollections bring us to the question that is at the heart of this paper: How do two fundamentally similar incidents and interactions lead to such different outcomes? 
To begin to answer this question, we suggest that, within this classroom, an affective plane emerged which shaped the ways in which these similar interactions were affected and affecting. Affective planes, as previously described, are the intangible inbetweens that connect us all, opening us up to and enhancing and constraining the ability to affect and be affected. Affects do not belong to individuals; rather, affective planes are deeply linked to the relations between people. This means that affective planes are more than the sum of individual people and events; instead, they connect all aspects of an event, reside in the context and processes through which our exchanges occur, and, on the limits of our consciousness, shape the ways in which we interact. In the vignettes above, we contend that while the cores of these exchanges were similar, the ways in which the gender of the subjects mattered were shaped by the affective plane. For instance, when a male colleague was challenged or interrupted, the exchange led to the complete disruption of knowledge production in the classroom, while when a woman was interrupted, the discussion and knowledge creation generally continued (albeit in a way that often excluded the viewpoints of those interrupted). We suggest that the particular affective plane that had emerged in this classroom played an important role in making such outcomes acceptable. This plane connected the students in the classroom so that interrupting and challenging a male student became unacceptable, to the extreme point of precluding the possibility of further knowledge production. When the same actions were directed toward female students, however, they were not meaningful enough (they did not affect enough) to halt discussion altogether.

While one could insist that the above incidents are just consequences of blatant sexism, we feel that this focus on affective planes is particularly useful because this process of making certain interactions "acceptable" and others "inacceptable" is not necessarily or always a conscious or governable process. We do not think that any of the individuals in the classroom believed that an action directed towards men should result in one consequence while the same action directed toward women should result in another. In fact, we continue to engage with many of the individuals from the class in our shared university community. We see these colleagues participating in feminist events on campus and advancing feminist issues through participation in organizations like the Graduate Student Association. Two of the male students have actually approached us on separate occasions, expressing a desire to learn more feminist theory in the form of a student-led discussion group. While these are, to some degree, anecdotal assessments of these individuals, we maintain that the classroom dynamics were therefore not the doing of conscious actions. Rather, we believe that there was something in the way in which we, as a collective, came together that produced these outcomes. Our collective and relational togetherness manifested in such a way that we were opened up to being affected by certain exchanges in gendered ways. The affective plane increased the potential (and therefore the actual manifestation) for problematic gendered social relations in this space, in which the acts, interactions, and exchanges related to one gender produced certain acceptable affects, while these same acts, interactions, and exchanges related to another gender produced different affects_-and thus outcomes—altogether.

Importantly, we wish to be clear that we do not think that affective planes can be separated from relations of power. The interpersonal and systemic relations of power that occur between different people are, instead, intimately tied to affects. For instance, there were undeniably gendered power dynamics at play in the incidents explored in the two vignettes (and in the class more generally): the fact that knowledge production ceased when male students were challenged or interrupted is undeniably tied to the systemic privileging of men (and subordination of women) as legitimate producers and holders of knowledge. Additionally, affective planes often emerge and change as a consequence of individual emotions, actions, and systems of power; individual sexist attitudes (whether explicit or implicit) will shape (and be shaped by) affective planes. These dynamics were clearly also at 
play in the classroom. For instance, a strong hostility towards "feminism" was explicitly demonstrated by two of the male students and one female student; when the discussion topic was "social reproduction," these students resorted to worn-out, simplistic descriptions of feminism ("All feminists are manhaters"), and the class quickly descended into a polarized confrontation. Subsequently, social reproduction and the theoretical insights of notable feminist political economists, such as Jane Jensen, Meg Luxton, and Spike Peterson, were not discussed in the class, as the professor tactfully intervened by challenging these problematic conceptualizations of feminism, albeit at the expense of discussing the assigned feminist texts in a meaningful way. Such hostility cannot be untied from gendered power relations and sexist norms and attitudes, nor can they be untied from the affective plane that we identify here.

Our point is rather quite the opposite: it is precisely in this mutual affected-affecting dynamic - this intertwinedness - that we feel the strength of affect, as an analytical tool, resides. Affect provides a way to move from the individual to the relational, to the ways in which collectives are opened (or not) to affecting and being affected. This contrasts with neoliberal ideology, which places the responsibility/blame for relational affects squarely on the individual (Jubas 2012, 46). An affective lens, on the other hand, allows us to move away from focusing on the individual actions and beliefs of specific people and towards the ways in which these actions and beliefs intermingle, co-exist, disrupt, and become "more than" through our relations with one another.

This "more than" is an especially important part of our analysis here, for despite several attempts to intervene and change the classroom climate by both the professor and various students, the particular affective plane that had emerged persisted throughout the course. For example, as mentioned above, the professor kept a speakers' list to ensure that all students were given space to voice their concerns and thoughts, and prioritized voices that were being silenced or diminished. He also held individual meet- ings with all of the students to address the classroom dynamics, and allowed Lauren to speak to the class as a whole about respect, safe spaces, and feminist pedagogy. Nonetheless, these individual attempts to intervene and disrupt this affective plane were not able to (re)shape this plane. Affects and affective planes are not the direct consequence of an action that can be manipulated accordingly. Rather, they are the sum and excess of our relations, our affections, and our affectedness. Although always at least partially affected by actions and interventions, they are impossible to control directly. By focusing on affective planes, aspects of our exchanges that are both on the edges of consciousness and more than the sum of individual thoughts and acts can be illuminated, interrogated, and better understood.

\section{Affective Exits and Openings}

An important consequence of these events was the ways in which they influenced knowledge production for the class as a collective, and for us as individual researchers. Deborah Gould (2009), for instance, highlights the importance of understanding how affect and emotions contribute to research and the process of knowledge production; while Gould is referring to how she was affectively moved by her field research, her point applies equally to other spaces of knowledge production. What about the affective planes of the classroom? What role do they play in processes of knowledge production? In this final section, we detail three ways the affective planes facilitated exits and openings that shaped the class as a whole and impacted us individually. We also draw out the broader implications of these exits and openings.

First, we suggest that under this affective plane, certain moments of tension led to conversational exits. This, we contend, was problematic, as working through moments of tension productively-as opposed to exiting tensions-is fundamental to what academics do, and to what we, as students, try to do in class settings. Tensions create space to challenge each other and ourselves, to unpack our deeply held 
assumptions and biases, and to flesh out our understandings of complex concepts and social phenomena. They are opportunities for researchers to address their own ontological and epistemological groundings (Smith 1987; 2005), and are therefore of great pedagogical import. Yet in this case study, these moments of tension moved away from potential sites of academic production and towards spaces of discomfort, resulting in conversational exits. For instance, as evidenced by vignette number one, when disagreements or disjunctures left the male colleagues in discomfort, class discussion ended, preventing any further useful theoretical discussions. In other words, in this affective space, male students were able to choose to exit certain conversations. On the other hand, when women were made uncomfortable during the discussion and by the classroom dynamics, the conversation largely continued, except now the female student was excluded from participating, as demonstrated by vignette number two. In this case, female students faced forced conversational exits. The affective plane in which we were working created a mutual affection in which chosen exits by men, and forced exits for women, seemed (or, indeed, were rendered) legitimate, even when the "formal rules" and course etiquette (as outlined on the course syllabus) suggest that students have a certain obligation to each other to try to engage with ideas and intellectual challenges respectively and inclusively. ${ }^{5}$

Second, and relatedly, we suggest that the affective climate that emerged in this classroom not only contributed to diminishing the voices of certain students, as described above, but also ensured that the topics and class content that were of interest to feminist students could not be the central drivers of knowledge production. The pedagogical and political consequences of this are significant, as the distinct knowledge sets and insights of feminist theory were excluded from the processes of knowledge creation; these knowledges and concerns had to exit the seminar. As shown in both vignettes, when men were uncomfortable, knowledge production ceased; when women were uncomfortable, knowledge production continued. Under this affective plane, male students had to feel comfortable and female students had to find avenues to deal with feeling uncomfortable for collective knowledge production to occur inside the classroom space. Any topic, issue, or idea that rendered men uncomfortable therefore had to exit the classroom. In this case, feminist issues and concerns seemed to make some male students uncomfortable, and were thus effectively forced to exit the seminar space, despite a strong presence on the course syllabus. This was demonstrated most forcibly during our week exploring social reproduction, as mentioned above.

Lastly, we suggest that this affective plane is also tied to our literal exit from the classroom. As our autoethnographic prelude explains, in response to the seminar's affective plane, and the affective manifestations of our class dynamics, we decided to meet outside of the classroom for a few hours every week to discuss course readings, presentations, and papers. We worked in our university's Graduate Student Association's lounge. We worked in coffee shops and bookstores. We occupied virtual space through text and Skype. During our sessions, we addressed questions that we had about the theories we were reading, the discussions that had unfolded during previous classes, and most importantly of all, we began to unpack the classroom dynamics. We tried to understand why we felt the way we had in the classroom space. We reflected on our emotions, as instantaneous assessments of affects, and from there we sought to understand more broadly our affective encounters in the seminar. Indeed, we laid the groundwork for what was eventually to become this paper.

In Living a Feminist Life (2017), Sara Ahmed provides guidance for understanding these exits and openings more broadly. As Ahmed writes, "The experience of being a feminist is often an experience of being out of tune with others" (40). Affect, as described and analyzed here, is part of what dictates being in and out of tune with others; it is that through which we orient ourselves to the people, places, and objects around us. The affective planes discussed in this paper left us "out of sync with a world" (Ahmed 2017, 41). Our 
voices and concerns were not in harmony with the collective affect of the class, and we ended up feeling out of place, and out of space. As Ahmed (2014) explains, "When attunement becomes an aim, those who are not in tune or who are out of tune become obstacles" (20). We felt like obstacles, bodies that were not at ease in that place (Ahmed 2017, 22). In response, we sought distance from that place, an exit.

However, as Ahmed (2017) reminds us, distance is sometimes needed to follow a thought. We need space to think through, to think-feel, and to begin to "redescribe the world we are in" (Ahmed 2017, 27). In our exit, our search for distance from the affective plane which rendered us "out of tune," we moved towards each other and towards new understandings of our experience in the classroom. This movement towards unfolded in a dual sense. On the one hand, we literally moved to a new space together, an opening where we could validate our feelings, where we could feel, once again, in tune. On the other hand, our exit also led us to a place where we could reflect on our bodily experience in a meaningful way. In other words, our exit provided an opening, somewhere to go, and allowed us to revisit where we have been (Ahmed 2017, 31). We could (re)think our experiences, we could begin to make sense of the world as we saw/felt it, and we could begin theorizing. This exit from the classroom, and opening to a new pedagogical space, echoes the tradition of feminist consciousness-raising (Firth and Robinson 2016), whereby those who are out of tune with the world come together and connect by forming "an account of oneself with and through others" (Ahmed 2017, 30). Our movement, our passing from exit to opening, and the affective planes which facilitated and shaped this movement, were part of the process through which we learned about the world which did not accommodate us (Ahmed 2017).

"Feminism as a collective movement," Ahmed writes, "is made out of how we are moved to become feminists in dialogue with others. A movement requires us to be moved" $(2017,5)$. Affect, in the classroom, in knowledge production, and beyond, can move us.
When we are affectively out of tune, we can exit. We can move towards openings. Through this movement, we affect and are affected. We gain capacity, accumulate affective value, so that we can ourselves become agents of movement, of change. And when we are ready, we can (re)enter; our theories, our knowledge, and our embodied being can move once again, perhaps this time decentering that which originally propelled us outwards.

\section{Acknowledgements}

The authors wish to thank Sacha Ghandeharian and the two peer reviewers for extremely helpful comments on an earlier version of this paper. They also wish to thank their feminist colleagues, including their supervisors and their doctoral peers, who have lifted them up. This work was supported by the Social Sciences and Humanities Research Council of Canada [grant number 767-2015-1242].

\section{Endnotes}

1. Notably, while compared to other, more traditional institutional ethnographic studies, we do not focus primarily on the ways in which texts coordinated the ruling relations in the classroom (e.g. Daniel 2008; Diamond 2009; Campbell and Gregor 2002). We do, however, acknowledge that, broadly speaking, the class was organized around the readings and student code of conduct put forth on the course syllabus.

2. For instance, in the historical materialist feminist tradition, socially reproductive labour is generally defined as "the complex of activities and relations by which our life and labour are daily reconstituted" (Federici 2012, 5). Similarly, Michael Hardt claims "affective labour is itself and directly the constitution of communities and collective subjectivities" (1999, 89), while Mignon Duffy asserts that care work is labour which provides for the basic needs of others in moments of dependency, thereby allowing the continuation of society (2011). In our view, these defini- 
tions, while attached to different terms, are referring to the same type of labour-or, at the very least, do not sufficiently demonstrate the differences between these activities.

3. This information is based on how students selfidentified/located themselves during the first class, during which each student presented some autobiographical information about themselves and their research by way of introduction.

4. As Ahmed (2017) writes, "Someone says something you consider problematic. At first you try not to say anything. But they keep saying something. So maybe you respond, carefully, perhaps. You say why you think what they have said is problematic. You might be speaking quietly, but you are beginning to feel wound up, recognizing with frustration that you are being wound up by someone who is winding you up. The feminist killjoy appears here: when she speaks, she seems wound up" (37).

5. This is not to suggest that students should be obliged to engage in harmful ideas, for instance, to entertain the legitimacy of a racist viewpoint.

\section{References}

Ahmed, Sara. 2004. "Affective Economies." Social Text 22(2): 117-139.

. 2014. "Not in the Mood." new formations: a journal of culture/theory/politics 82: 13-28.

2017. Living a Feminist Life. Durham: Duke University Press.

Anderson, Ben. 2006. "Becoming and Being Hopeful: Towards a Theory of Affect." Environment and Planning D: Society and Space 24: 733-752.

Anderson, Ben, and Adam Holden. 2008. "Affective Urbanism and the Event of Hope." Space and Culture 11: 142-159.

Baker, Maureen. 2012. "Gendered Families, Academic Work and the 'Motherhood Penalty." Women's Studies Journal 26(1): 11-24.

Bondi, Liz. 2003. "Empathy and Identification: Conceptual Resources for Feminist Fieldwork." ACME 2(1): 64-76.

Campbell, Marie, and Frances Mary Gregor. 2008. Mapping Social Relations: A Primer in Doing Institutional Ethnography. Toronto: University of Toronto Press.

Caplan, Paula J. 1993. Lifting a Ton of Feathers: A Woman's Guide to Surviving in the Academic World. Toronto: University of Toronto Press.

Chang, Heewon. 2008. Autoethnography as Method. Walnut Creek, CA: Left Coast Press.

Coleman, Major G. 2005. "Racism in Academia: The White Superiority Supposition in the 'Unbiased' Search for Knowledge." European Journal of Political Economy 21(3): 762-774. 
Cvetkovich, Ann. 2012. Depression: A Public Feeling. Durham, NC: Duke University Press.

Daniel, Yvette. 2008. “The 'Textualized' Student: An Institutional Ethnography of a Funding Policy for Students with Special Needs in Ontario." In People at Work: Life, Power, and Social Inclusion in the New Economy, ed. by M. Devault, 248-266. New York: New York University.

Diamond, Timothy. 2009. Making Gray Gold: Narratives of Nursing Home Care. Chicago and London: University of Chicago Press.

Duffy, Mignon. 2011. Making Care Count. London: Routledge.

Dutta, Mohan. 2018. "Autoethnography as Decolonization, Decolonizing Autoethnography: Resisting to Build Our Homes." Cultural Studies <-> Critical Methodologies 18(1): 94-96.

Ellis, Carolyn, and Arthur P. Bochner. 2000.

"Autoethnography, Personal Narrative, Reflexivity." In Handbook of Qualitative Research, 2nd edition, ed. by N. K. Denzin and Y. S. Lincoln, 733-768. Thousand Oaks, CA: Sage Publications.

Ellis, Carolyn, Tony E. Adams, and Arthur P. Bochner. 2011. "Autoethnography: An Overview." Forum Qualitative Sozialforschung/Forum: Qualitative Social Research 12(1): Article 10.

Federici, Silvia. 2012. Revolution at Point Zero. Oakland, CA: PM Press.

Firth, Rhiannon, and Andrew Robinson. 2016. "For a Revival of Feminist Consciousness-Raising: Horizontal Transformation of Epistemologies and Transgression of Neoliberal TimeSpace." Gender and Education 28(3): 343-358.

Gannon, Susanne, Giedre Kligyte, Jan McLean, Maud Perrier, Elaine Swan, Ilaria Vanni, and Honni van Rijswijk. 2015. "Uneven Relationalities,
Collective Biography, and Sisterly Affect in Neoliberal Universities." Feminist Formations 27(3): 189-216.

Gould, Deborah. 2009. Moving Politics: Emotion and ACT UP's Fight against AIDS. Chicago: University of Chicago Press.

Hardt, Michael. 1999. "Affective Labor." boundary 26(2): 89-100.

Heidegger, Martin. 1995. The Fundamental Concepts of Metaphysics: World, Finitude, Solitude. Translated by William McNeill and Nicholas Walker. Bloomington: Indiana University Press.

Holstein, James and Jaber Gubrium. 1997. "Active Interviewing." In Qualitative Research: Theory, Method, and Practice, ed. by D. Silverman, 113-129. Thousand Oaks, CA: Sage Publications.

hooks, bell. 1994. Teaching to Transgress: Education as a Practice of Freedom. New York: Routledge.

Jubas, Kaela. 2012. "On Being a New Academic in the New Academy: Impacts of Neoliberalism on Work and Life of a Junior Faculty Member." Workplace: A Journal for Academic Labor 21: 25-35.

Jubas, Kaela, and Jackie Seidel. 2016. "Knitting as Metaphor for Work: An Institutional Autoethnography to Surface Tensions of Visibility and Invisibility in the Neoliberal Academy." Journal of Contemporary Ethnography 45(1): 60-84.

Jupp, Victor. 2006. The Sage Dictionary of Social Research Methods. London: Sage Publications.

Kelly, Gail P., and Sheila Slaughter. 1991. "Women and Higher Education: Trends and Perspectives." In Women's Higher Education in Comparative Perspective, ed. by G. P. Kelly and S. Slaughter, 3-13. Dordrecht: Kluwer Academic Publishers.

Kinsman, Gary, and Patrizia Gentile. 2010. The Canadian War on Queers: National Security as Sexual Regulation. Vancouver: UBC Press. 
Kobayashi, Audrey. 1994. "Coloring the Field:

Gender, 'Race,' and the Politics of Fieldwork." The

Professional Geographer 46(1): 73-80.

Kyvik, Svein, and Mari Teigen. 1996. "Child Care, Research Collaboration, and Gender Differences in Scientific Productivity." Science, Technology and Human Values 21(1): 54-71.

Mintz, Beth, and Esther Rothblum, eds. 1997. Lesbians in Academia: Degrees of Freedom. New York: Routledge.

Philips, John. 2006. "Agencement/Assemblage."

Theory, Culture, and Society 23(2-3): 108-109.

Seigworth, Gregory J. 2000. "Banality for Cultural Studies." Cultural Studies 14(2): 227-268.

Smith, Dorothy. 1987. The Everyday World as Problematic: A Feminist Sociology. Toronto, Ontario: University of Toronto Press. . 2005. Institutional Ethnography: A Sociology for People. Lanham, MD: AltaMira Press.

Spry, Tami. 2001. "Performing Autoethnography." Qualitative Inquiry 7(6): 706-732.

Taber, Nancy. 2010. "Institutional Ethnography, Autoethnography, and Narrative: An Argument for Incorporating Multiple Methodologies." Qualitative Research 10(1):5-25.

Tullis Owen, Jillian A., Chris McRae, Tony E. Adams, and Alisha Vitale. 2009. "Truth Troubles." Qualitative Inquiry 15(1): 178-200.

Uhly, Katrina M., Laura M. Visser, and Kathrin S. Zippel. 2017. "Gendered Patterns in International Research Collaborations in Academia." Studies in Higher Education 42(4): 760-782.
Wilson, Shawn. 2008. Research is Ceremony. Halifax: Fernwood Publishing. 